\title{
Prevalence, characterization, and antimicrobial resistance of Yersinia species and Yersinia enterocolitica isolated from raw milk in farm bulk tanks
}

\author{
Hossein Jamali, ${ }^{1}$ Mohammadjavad Paydar, $†$ Behrad Radmehr, $\ddagger$ and Salmah Ismail* \\ *Biohealth Science Program, Institute of Biological Science, Faculty of Science, and \\ †Department of Pharmacology, Faculty of Medicine, University of Malaya, Kuala Lumpur, 50603 Kuala Lumpur, Malaysia \\ $\ddagger$ Department of Food Hygiene and Quality Control, Faculty of Veterinary Medicine, Islamic Azad University-Karaj Branch, Karaj 31485-313, Iran
}

\begin{abstract}
The aims of this study were to investigate the prevalence and to characterize and determine the antibiotic resistance of Yersinia spp. isolates from raw milk. From September 2008 to August 2010, 446 raw milk samples were obtained from farm bulk milk tanks in Varamin, Iran. Yersinia spp. were detected in 29 (6.5\%) samples, out of which $23(79.3 \%), 5(17.2 \%)$, and $1(3.4 \%)$ were isolated from cow, sheep, and goat raw milk, respectively. The most common species isolated was Yersinia enterocolitica $(65.5 \%)$, followed by Yersinia frederiksenii (31\%), and Yersinia kristensenii (3.4\%). Of the 19 $Y$. enterocolitica isolates, $14(73.7 \%)$ were grouped into bioserotype 1A/O:9, 4 (21.1\%) belonged to bioserotype 1B:O8, 1 (5.3\%) belonged to bioserotype 4/O:3, and 1 isolate (biotype 1A) was not typable. All the isolates of biotypes $1 \mathrm{~B}$ and 4 harbored both the ystA and ail genes. However, all the isolates of biotype $1 \mathrm{~A}$ were only positive for the ystB gene. The tested Yersinia spp. showed the highest percentages of resistance to tetracycline $(48.3 \%)$, followed by ciprofloxacin and cephalothin (each $17.2 \%$ ), ampicillin (13.8\%), streptomycin (6.9\%), and amoxicillin and nalidixic acid (each 3.4\%). All of the tested isolates demonstrated significant sensitivity to gentamicin and chloramphenicol. Recovery of potentially pathogenic $Y$. enterocolitica from raw milk indicates high risks of yersiniosis associated with consumption of raw milk.
\end{abstract}

Key words: Yersinia spp., virulence gene, bioserotype, antimicrobial resistance, raw milk

\section{INTRODUCTION}

The genus Yersinia is gram-negative and belongs to the family of Enterobacteriaceae. It comprises at least 16 species. Among them, Yersinia pestis, Yersinia pseudotuberculosis, and Yersinia enterocolitica are con-

Received September 15, 2014.

Accepted October 29, 2014.

${ }^{1}$ Corresponding author: mordabenilofari@gmail.com sidered the most important human pathogenic species (von Tils et al., 2012). Yersinia enterocolitica is an important foodborne pathogen in humans and is primarily transmitted through consumption of contaminated pork, milk, or water (Thoerner et al., 2003).

Milk is an important source of nutrients for humans (Sharma and Joshi, 1992). Several outbreaks of enteric infections caused by consumption of contaminated raw milk have been documented (Tacket et al., 1984; Barrett, 1986; Ackers et al., 2000). Yersinia enterocolitica is able to survive at refrigeration temperature and, consequently, consumption of contaminated milk with the pathogen could be considered a public health risk. Although, $Y$. enterocolitica is well known as a cause of yersiniosis in children (Hoogkamp-Korstanje and StolkEngelaar, 1995), the infection has been found infrequently in Iran, where pork is never used (Bashiribod, 1989). This microorganism is ubiquitous in nature and has been isolated from different types of foods, animals, and environments (Fredriksson-Ahomaa and Korkeala, 2003).

Although, numerous $Y$. enterocolitica biotypes have been isolated from nature, only a few are human pathogens (Weagant and Feng, 2001). Yersinia enterocolitica includes nonpathogenic biotype 1A (Bottone, 1997) and pathogenic biotypes 1B, 2, 3, 4, and 5 (Thoerner et al., 2003). Pigs are the main reservoirs and vehicles for $Y$. enterocolitica transmission (Fredriksson-Yhomaa et al., 2006), but virulent strains have been also detected in milk and dairy products (Soltan-Dallal et al., 2004; Hanifian and Khani, 2012). The presence of virulence plasmids was applied for the evaluation of the pathogenicity of $Y$. enterocolitica isolates (Platt-Samoraj et al., 2006). Virulence genes, such as ail and yst, are located on the bacterial chromosome (Miller et al., 1989; Grant et al., 1998; Gierczynski, 2000). The Ail protein is encoded by the ail gene and only occurs in pathogenic $Y$. enterocolitica; it contributes in bacterial adhesion to the host cell as well as intensifies resistance to the bactericidal effects of complement (Mors and Pai, 1980; Miller et al., 1989; Miller et al., 1990; Bleves and Cornelis, 2000; Gierczynski, 2000; Thoerner et al., 
2003). Moreover, the yst gene, which encodes the thermostable enterotoxin Yst protein, facilitates the invasion of the pathogen into tissues (Robins-Browne et al., 1979; Ibrahim et al., 1997; Ramamurthy et al., 1997; Gierczynski, 2000; Revell and Miller, 2001). The YstA and YstB are produced by pathogenic and nonpathogenic $Y$. enterocolitica, respectively (Mikulskis et al., 1994; Ramamurthy et al., 1997; Singh and Virdi, 2004). However, studies on the prevalence and resistance profiles of Yersinia spp. in raw milk in Iran are lacking (Hanifian and Khani, 2012) and no clear picture of the risks associated with consumption of raw milk exists. Hence, the current study was carried out to investigate the prevalence and to characterize and determine the antimicrobial resistance status of Yersinia spp. isolates from raw milk in Tehran province, Iran.

\section{MATERIALS AND METHODS}

\section{Sample}

A total of 446 raw milk samples, including 240 cow milk samples, 165 sheep milk samples, and 41 goat milk samples, were aseptically collected from farm bulk milk tanks in Varamin, Tehran province, Iran, from September 2008 to August 2010. Transportation of the samples to the laboratory was done in ice boxes within $4 \mathrm{~h}$ after collection (Jamali et al., 2013).

\section{Isolation and Detection}

Isolation and detection of Yersinia spp. were done according to Yucel and Ulusoy (2006). Five milliliters of each sample was added to $45 \mathrm{~mL}$ of Tris-buffered peptone water (10 $\mathrm{g}$ of peptone, $12.1 \mathrm{~g}$ of Tris methylamine, $5 \mathrm{~g}$ of sodium chloride, $\mathrm{pH}$ 8.4) and the samples were incubated for $3 \mathrm{wk}$ at $4^{\circ} \mathrm{C}$. One milliliter of each cold enriched broth was treated with $9 \mathrm{~mL}$ of a $0.25 \% \mathrm{KOH}$ solution $(0.25 \% \mathrm{KOH}$ in $0.5 \% \mathrm{NaCl})$ to repress background microbiota at 7, 14, and $21 \mathrm{~d}$. Then, a loopful of the mixture was streaked on cefsulodinirgasan-novobiocin agar (Oxoid, Basingstoke, UK) and incubated for $24 \mathrm{~h}$ at $30^{\circ} \mathrm{C}$. The presumptive isolates were examined for biochemical tests as reported by Greenwood and Hooper (1989), Feeley and Schiemann (1984). The isolates were further identified by using the API 20E according to the guideline of the manufacturer (bioMérieux, Marcy l'Etoile, France).

\section{Biotyping and Serotyping}

The $Y$. enterocolitica isolates were biotyped by discriminatory tests (lipase, xylose, indole, esculin, trehalose, and salicin; Wauters et al., 1987). The serotype of the isolates was also determined by using commercial serum agglutinant O-Antisera (Bio-Rad, Marnes-laCoquette, France).

\section{Detection of Virulence Genes by Multiplex PCR}

Detection of the ail, yst $A$, and $y s t B$ genes was carried out using a multiplex PCR as described by PlattSamoraj et al. (2006).

\section{Antimicrobial Susceptibility Testing}

The Kirby-Bauer disc diffusion method on Mueller Hinton agar (Oxoid) was applied to determine the antimicrobial susceptibility as described in Clinical and Laboratory Standards Institute (CLSI, 2006). The panel of applied antimicrobial agents and concentrations was as follows: trimethoprim $(15 \mu \mathrm{g})$, ciprofloxacin (5 $\mu \mathrm{g})$, tetracycline $(15 \mu \mathrm{g})$, gentamicin $(10 \mu \mathrm{g})$, nalidixic acid $(30 \mu \mathrm{g})$, streptomycin $(30 \mu \mathrm{g})$, chloramphenicol $(30 \mu \mathrm{g})$, ampicillin $(30 \mu \mathrm{g})$, amoxicillin $(30 \mu \mathrm{g})$, and cephalothin $(30 \mu \mathrm{g})$.

\section{Statistical Analysis}

Chi-squared analysis was applied to analyze the corelationship among contaminated samples and various types of raw milk. The statistical and Chi-squared analyses were done via SPSS 18.0 (SPSS Inc., Chicago, IL). A $P$-value $<0.05$ was used for statistical significance.

\section{RESULTS}

In the present study, $6.5 \%$ (29 out of 446 ) of the tested raw milk samples harbored Yersinia spp., and the prevalence of $Y$. enterocolitica, $Y$. frederiksenii, and $Y$. kristensenii were $65.5,31$, and $3.4 \%$, respectively. Among the 446 samples, 23 (9.6\% of cow milk samples), 5 (3\% of sheep milk samples), and 1 ( $2.4 \%$ of goat milk samples) cow, sheep, and goat raw milk samples were contaminated with Yersinia spp. (Table 1). A significant difference was found between contaminated raw cow milk samples with Yersinia spp. and other kinds of raw milk $(P<0.05)$.

The $19 Y$. enterocolitica isolates from raw milk samples were distributed into biotype 1A (78.9\%), biotype 1B (15.8\%), and biotype 4 (5.3\%). The tested Y. enterocolitica isolates were further grouped into serotypes O:9 (bioserotype 1A/O:9; 73.3\%), O:8 (bioserotype 1B/O:8; 15.8\%), O:3 (bioserotype 4/O:3; 5.3\%), and 1 isolate (biotype $1 \mathrm{~A}$ ) was not typable (Table 2 ).

The $y s t A$ gene was observed in all the isolates having bioserotypes $1 \mathrm{~B} / \mathrm{O}: 8$ or $4 / \mathrm{O}: 3$. However, the ail gene 
Table 1. Prevalence of Yersinia spp. in raw milk samples (values in parentheses indicate \% of samples positive within each type of milk)

\begin{tabular}{lccccc}
\hline Item & No. of samples & Yersinia spp. & $\begin{array}{c}\text { Yersinia } \\
\text { enterocolitica }\end{array}$ & $\begin{array}{c}\text { Yersinia } \\
\text { frederiksenii }\end{array}$ & $\begin{array}{c}\text { Yersinia } \\
\text { kristensenii }\end{array}$ \\
\hline Cow milk & 240 & $23(9.6 \%)$ & $14(5.8 \%)$ & $8(3.3 \%)$ & $1(0.4 \%)$ \\
Sheep milk & 165 & $5(3 \%)$ & $4(2.4 \%)$ & $1(0.6 \%)$ & - \\
Goat milk & 41 & $1(2.4 \%)$ & $1(2.4 \%)$ & - & - \\
Total & 446 & $29(6.5 \%)$ & $19(4.3 \%)$ & $9(2 \%)$ & $1(0.2 \%)$ \\
\hline
\end{tabular}

was only detected from biotype 4/O:3 and all isolates of $Y$. enterocolitica biotype $1 \mathrm{~A}$ harbored only the ystB gene (Table 2).

The resistance profiles of Yersinia spp. in our study are shown in Table 3. The results showed that 17 isolates $(58.6 \%)$ of Yersinia spp. indicated significant resistance to 1 or 2 of the tested antimicrobial agents. Moreover, multi-drug resistance was observed in 2 of the Yersinia spp. isolates (6.9\%; Figure 1). The isolates of Yersinia spp. were resistant to tetracycline (48.3\%), ciprofloxacin, and cephalothin (each 17.2\%). All the Yersinia spp. isolates were susceptible to gentamicin and chloramphenicol.

\section{DISCUSSION}

Yersiniosis is a zoonotic disease with a wide distribution and a known public health significance; it is one of the most frequently reported zoonosis in the European Union (EFSA, 2007). Although raw milk and homemade dairy products, such as unripened traditional cheese, are commonly consumed in Iran, there are few studies on the prevalence and characterization of $Y$. enterocolitica in raw milk (Hanifian and Khani, 2012).

Among the different types of raw milk samples analyzed in the present study, the highest percentage of $Y$. enterocolitica $(5.8 \%)$ was observed in cow milk. The pathogen was isolated from $2.3 \%$ of raw cow milk in northern Iran (Soltan-Dallal et al., 2004). In another study, Hanifian and Khani (2012) detected the virulent $Y$. enterocolitica in $7.6 \%$ of raw cow milk samples in northwest Iran. Yersinia enterocolitica was also isolated from cow, sheep, and goat raw milk in other countries (Yucel and Ulusoy, 2006; El-Aal and Atta, 2009; Schoder et al., 2010; Bernardino-Varo et al., 2013). Four percent of raw milk cheese samples were contaminated with $Y$. enterocolitica in Morocco (Hamama et al., 1992). The frequency of $Y$. frederiksenii $(2 \%)$ and $Y$. kristensenii $(0.2 \%)$ isolation in our study was lower as compared with other studies of raw milk in Turkey and Mexico by Yucel and Ulusoy (2006) and Bernardino-Varo et al. (2013). Inadequate hygiene in dairy farms, particularly during milking, could probably be a source of Yersinia spp. in raw milk (Hanifian and Khani, 2012). The pres-

Table 2. Biotyping, serotyping, and PCR analysis of ail, ystA, and ystB genes in isolates of Yersenia enterocolitica

\begin{tabular}{lcccccc}
\hline $\begin{array}{l}\text { Isolation } \\
\text { code }\end{array}$ & $\begin{array}{l}\text { Milk } \\
\text { type }\end{array}$ & Biotype & Serotype & ail & ystA & ystB \\
\hline Y-C-1 & Cow & 1A & O:9 & - & - & + \\
Y-C-2 & Cow & 1A & O:9 & - & - & + \\
Y-C-3 & Cow & 1B & O:8 & - & + & - \\
Y-C-4 & Cow & 1A & O:9 & - & - & + \\
Y-C-5 & Cow & 1A & Not typable & - & - & + \\
Y-C-6 & Cow & 1A & O:9 & - & - & - \\
Y-C-7 & Cow & 1A & O:9 & - & - & + \\
Y-C-8 & Cow & 1A & O:9 & - & - & + \\
Y-C-9 & Cow & 1B & O: & - & + & - \\
Y-C-10 & Cow & 1B & O:8 & - & + & - \\
Y-C-11 & Cow & 1A & O:9 & - & - & + \\
Y-C-12 & Cow & 4 & O:3 & + & + & - \\
Y-C-13 & Cow & 1A & O:9 & - & - & + \\
Y-C-14 & Cow & 1A & O:9 & - & - & + \\
Y-S-1 & Sheep & 1A & O:9 & - & - & + \\
Y-S-2 & Sheep & 1A & O:9 & - & - & + \\
Y-S-3 & Sheep & 1A & O:9 & - & - & + \\
Y-S-4 & Sheep & 1A & O:9 & - & - & - \\
Y-G-1 & Goat & 1A & O:9 & - & - & + \\
\hline
\end{tabular}


Table 3. Antimicrobial resistance profiles of Yersinia spp. isolated from raw milk samples (values in parentheses indicate $\%$ of isolates resistant to each agent)

\begin{tabular}{lcccc}
\hline $\begin{array}{l}\text { Antimicrobial } \\
\text { agent }\end{array}$ & $\begin{array}{c}\text { Yersinia } \\
\text { spp. }(29)\end{array}$ & $\begin{array}{c}\text { Yersinia } \\
\text { enterocolitica (19) }\end{array}$ & $\begin{array}{c}\text { Yersinia } \\
\text { frederiksenii (9) }\end{array}$ & $\begin{array}{c}\text { Yersinia } \\
\text { kristensenii (1) }\end{array}$ \\
\hline $\begin{array}{l}\text { Tetracycline } \\
\text { Chloramphenicol }\end{array}$ & $14(48.3 \%)$ & $10(52.6 \%)$ & $4(44.4 \%)$ & - \\
Amoxicillin & $1(3.4 \%)$ & $1(5.3 \%)$ & - & - \\
Ampicillin & $4(13.8 \%)$ & $3(15.8 \%)$ & $1(11.1 \%)$ & - \\
Gentamicin & - & - & - & - \\
Streptomycin & $2(6.9 \%)$ & $2(10.5 \%)$ & - & - \\
Ciprofloxacin & $5(17.2 \%)$ & $5(26.3 \%)$ & - & - \\
Nalidixic acid & $1(3.4 \%)$ & $1(5.3 \%)$ & - & - \\
Cephalothin & $5(17.2 \%)$ & $3(15.8 \%)$ & - & - \\
Trimethoprim-sulfonamide & $2(6.9 \%)$ & $2(10.5 \%)$ & - & - \\
\hline
\end{tabular}

ence of Yersinia spp. in our study concurred with the previous findings and further confirmed the yersiniosis risks associated with consumption of unpasteurized milk.

In the present study, 3 bioserotypes (1A/O:9, 1B/O:8, and 4/O:3) were identified and, among them, 1A/O:9 was the most predominant $Y$. enterocolitica bioserotype. The high percentage rate of bioserotype 1A/O:9 in raw milk is congruent with earlier findings in Iran (SoltanDallal et al., 2004) and other countries (BernardinoVaro et al., 2013). Although Y. enterocolitica biotype 1A, Y. frederiksenii, and Y. kristensenii are considered as environmental organisms that are nonpathogenic, these organisms could generate infection by virtue of virulence factors distinct from those of other $Y$. enterocolitica (Sulakvelidze, 2000). The pathogenic bioserotypes 1B/O:8 and 4/O:3 of $Y$. enterocolitica were only isolated from cow raw milk in the present study. These pathogenic bioserotypes were also isolated from animal and animal food origin in previous studies (Bonardi et al., 2013; Tan et al., 2014).

The YstA and Ail proteins are important factors for $Y$. enterocolitica virulence. Hence, the existence of the yst $A$ and ail genes, which encode these proteins, are used as appropriate pathogenicity markers of $Y$. enterocolitica isolates (Miller et al., 1989; Grant et al., 1998; Gierczynski, 2000; Thoerner et al., 2003). All the $Y$. enterocolitica isolates from raw milk samples were examined for the presence of the genes by PCR. The ail and ystA genes were detected in all isolates of bioserotypes 1B/O:8 and 4/O:3, which confirms previous findings (Grant et al., 1998; Thoerner et al., 2003; Platt-Samoraj et al., 2006; Bancerz-Kisiel et al., 2012). Conversely, all 15 isolates of biotype $1 \mathrm{~A}$ harbored the $y s t B$ gene. In the previous studies, the $y s t B$ gene was found in $100,87.3$, and $80 \%$ of $Y$. enterocolitica biotype 1A isolated from aborted fetuses (Platt-Samoraj et al., 2006), feces of animals (Grant et al., 1998), and

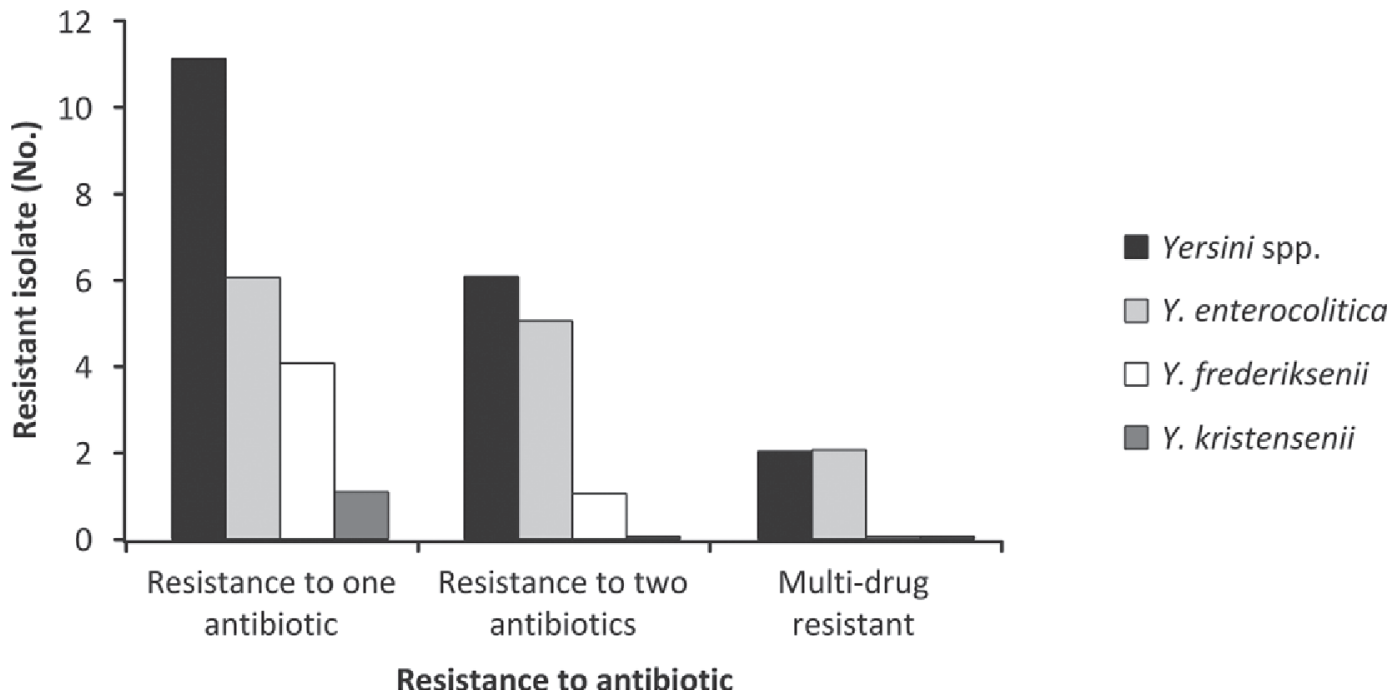

Figure 1. Percentage resistance of Yersinia spp. isolated from raw milk against selected antibiotics.. 
humans, food, and the environment (Thoerner et al., 2003), respectively.

High resistance of Yersinia isolates to tetracycline in our study is in agreement with earlier findings (Subha et al., 2009). However, in another study, isolates of Yersinia were susceptible to tetracycline (Pham et al., 1995). Furthermore, high resistance of isolated Yersinia spp. from poultry to cephalothin and ampicillin was also observed in previous studies in Tehran Province, Iran (Soltan-Dallal et al., 2010; Jamali et al., 2014). A variety of antimicrobial agents are used against microbial infection and as growth promoters in animals. Excessive administrations of these agents have recently led to an upward trend in the incidence of antimicrobial-resistant isolates of microorganisms (Jamali et al., 2013). Tetracycline is commonly applied in animal food to control and treat infectious diseases in dairy farms in Iran. Hence, the significant resistance rates of the pathogen to tetracycline might be attributed to widespread application of the antibiotic (Jamali et al., 2013). Conversely, the presence of antimicrobialresistant Yersinia in foods, especially in milk and the potential transmission of the pathogen with contaminated food, could be a public health concern for the consumers.

In summary, recovery of potentially pathogenic $Y$. enterocolitica from raw milk samples showed that consumption of raw milk may be a potential risk of yersiniosis. Therefore, further investigations on the prevalence of $Y$. enterocolitica as well as emerging antibiotic resistance are needed to enable the recognition of foods with significant risks and also to ensure effective treatments against yersiniosis.

\section{ACKNOWLEDGMENTS}

This study was supported by OCAR chancellery of the University of Malaya with grant number A21010-DA674 and A-21010-DA677.

\section{REFERENCES}

Ackers, M.-L., S. Schoenfeld, J. Markman, M. G. Smith, M. A. Nicholson, W. DeWitt, D. N. Cameron, P. M. Griffin, and L. Slutsker. 2000. An outbreak of Yersinia enterocolitica O: 8 infections associated with pasteurized milk. J. Infect. Dis. 181:1834-1837.

Bancerz-Kisiel, A., A. Szczerba-Turek, A. Platt-Samoraj, and W. Szweda. 2012. Distribution of the ymoA and ystA genes and enterotoxins Yst production by Yersinia enterocolitica strains isolated from humans and pigs. Pol. J. Vet. Sci. 15:609-614.

Barrett, N. J. 1986. Communicable disease associated with milk and dairy products in England and Wales: 1983-1984. J. Infect. $12: 265-272$.

Bashiribod, H. 1989. Serological investigations of children in Iran for Campylobacter, Yersinia and Shigella. Geogr. Med. Suppl. 5:205206.
Bernardino-Varo, L., E. I. Quinones-Ramirez, F. J. Fernandez, and C. Vazquez-Salinas. 2013. Prevalence of Yersinia enterocolitica in raw cow's milk collected from stables of Mexico City. J. Food Prot. 76:694-698.

Bleves, S., and G. R. Cornelis. 2000. How to survive in the host: the Yersinia lesson. Microbes Infect. 2:1451-1460.

Bonardi, S., L. Bassi, F. Brindani, M. D'Incau, L. Barco, E. Carra, and S. Pongolini. 2013. Prevalence, characterization and antimicrobial susceptibility of Salmonella enterica and Yersinia enterocolitica in pigs at slaughter in Italy. Int. J. Food Microbiol. 163:248-257.

Bottone, E. J. 1997. Yersinia enterocolitica: The charisma continues. Clin. Microbiol. Rev. 10:257-276.

CLSI. 2006. Methods for Antimicrobial Dilution and Disk Susceptibility Testing of Infrequently Isolated or Fastidious Bacteria; Approved Guideline (M45-A). Clinical and Laboratory Standards Institute, Wayne, PA.

EFSA. 2007. Monitoring and identification of human enteropathogenic Yersinia spp. Scientific opinion of the panel of biological hazards. The EFSA Journal 595:1-30.

El-Aal, S., and M. Atta. 2009. Occurrence of Listeria and Yersinia species in milk and some milk products. Assiut Vet. Med. J. 55:45-60.

Feeley, J., and D. Schiemann. 1984. Yersinia. Pages 351-367 in Compendium of Methods for the Microbiological Examination of Foods, 2nd ed. M. Speck, ed. American Public Health Association, Washington, DC

Fredriksson-Ahomaa, M., and H. Korkeala. 2003. Low occurrence of pathogenic Yersinia enterocolitica in clinical, food, and environmental samples: A methodological problem. Clin. Microbiol. Rev. $16: 220-229$.

Fredriksson-Ahomaa, M., A. Stolle, and H. Korkeala. 2006. Molecular epidemiology of Yersinia enterocolitica infections. FEMS Immunol. Med. Microbiol. 47:315-329.

Gierczynski, R. 2000. Assessment of the usefulness of selected markers for the identification of pathogenic Yersinia enterocolitica strains. III. Chromosomal virulence markers. Med. Dosw. Mikrobiol. 52:51-65. (in Polish).

Grant, T., V. Bennett-Wood, and R. M. Robins-Browne. 1998. Identification of virulence-associated characteristics in clinical isolates of Yersinia enterocolitica lacking classical virulence markers. Infect. Immun. 66:1113-1120.

Greenwood, M. H., and W. Hooper. 1989. Improved methods for the isolation of Yersinia species from milk and foods. Food Microbiol. 6:99-104.

Hamama, A., A. El Marrakchi, and F. El Othmani. 1992. Occurrence of Yersinia enterocolitica in milk and dairy products in Morocco. Int. J. Food Microbiol. 16:69-77.

Hanifian, S., and S. Khani. 2012. Prevalence of virulent Yersinia enterocolitica in bulk raw milk and retail cheese in northern-west of Iran. Int. J. Food Microbiol. 155:89-92.

Hoogkamp-Korstanje, J. A., and V. M. Stolk-Engelaar. 1995. Yersinia enterocolitica infection in children. Pediatr. Infect. Dis. J. 14:771-775.

Ibrahim, A., W. Liesack, M. Griffith, and R. Robins-Browne. 1997. Development of a high specific assay for rapid identification of pathogenic strains of Yersinia enterocolitica based on PCR amplification of the Yersinia heat-stable enterotoxin gene (yst). J. Clin. Microbiol. 35:1636-1638.

Jamali, H., B. Radmehr, and S. Ismail. 2014. Prevalence and antimicrobial resistance of Listeria, Salmonella, and Yersinia species isolates in ducks and geese. Poult. Sci. 93:1023-1030.

Jamali, H., B. Radmehr, and K. L. Thong. 2013. Prevalence, characterisation, and antimicrobial resistance of Listeria species and Listeria monocytogenes isolates from raw milk in farm bulk tanks. Food Contr. 34:121-125.

Mikulskis, A. V., I. Delor, V. Thi, and G. Cornelis. 1994. Regulation of the Yersinia enterocolitica yst gene. Influence of growth phase, temperature, osmolarity, $\mathrm{pH}$ and bacterial host factors. Mol. Microbiol. 14:905-915. 
Miller, V. L., J. Bliska, and S. Falkow. 1990. Nucleotide sequence of the Yersinia enterocolitica ail gene and characterization of the Ail protein product. J. Bacteriol. 172:1062-1069.

Miller, V. L., J. Farmer, W. Hill, and S. Falkow. 1989. The ail locus is found uniquely in Yersinia enterocolitica serotypes commonly associated with disease. Infect. Immun. 57:121-131.

Mors, V., and C. Pai. 1980. Pathogenic properties of Yersinia enterocolitica. Infect. Immun. 28:292-294.

Pham, J. N., S. Bell, M. Hardy, L. Martin, A. Guiyoule, and E. Carniel. 1995. Susceptibility to beta-lactam agents of Yersinia enterocolitica biotype 4, serotype O3 isolated in various parts of the world. J. Med. Microbiol. 43:9-13.

Platt-Samoraj, A., M. Ugorski, W. Szweda, A. Szczerba-Turek, K. Wojciech, and Z. Procajło. 2006. Analysis of the presence of ail, $y s t A$ and $y s t B$ genes in Yersinia enterocolitica strains isolated from aborting sows and aborted fetuses. J. Vet. Med. B Infect. Dis. Vet. Public Health 53:341-346.

Ramamurthy, T., K.-i. Yoshino, X. Huang, G. Balakrish Nair, E. Carniel, T. Maruyama, H. Fukushima, and T. Takeda. 1997. The novel heat-stable enterotoxin subtype gene (ystB) of Yersinia enterocolitica: Nucleotide sequence and distribution of the yst genes. Microb. Pathog. 23:189-200.

Revell, P. A., and V. L. Miller. 2001. Yersinia virulence: More than a plasmid. FEMS Microbiol. Lett. 205:159-164.

Robins-Browne, R. M., C. Still, M. Miliotis, and H. Koornhof. 1979. Mechanism of action of Yersinia enterocolitica enterotoxin. Infect. Immun. 25:680-684.

Schoder, D., A. Zangana, and M. Wagner. 2010. Sheep and goat raw milk consumption: A hygienic matter of concern? Arch. Lebensmittelhyg. 61:229-234.

Sharma, D., and D. Joshi. 1992. Bacteriological quality of milk and milk products with special reference to Salmonella and its public health significance. J. Food Sci. Technol. 29:105-107.

Singh, I., and J. S. Virdi. 2004. Production of Yersinia stable toxin (YST) and distribution of yst genes in biotype 1A strains of Yersinia enterocolitica. J. Med. Microbiol. 53:1065-1068.

Soltan-Dallal, M. M., M. P. Doyle, M. Rezadehbashi, H. Dabiri, M. Sanaei, S. Modarresi, R. Bakhtiari, K. Sharifiy, M. Taremi, and M. R. Zali. 2010. Prevalence and antimicrobial resistance profiles of Salmonella serotypes, Campylobacter and Yersinia spp. isolated from retail chicken and beef, Tehran, Iran. Food Contr. 21:388392.

Soltan-Dallal, M.-M., A. Tabarraie, and K. MoezArdalan. 2004. Comparison of four methods for isolation of Yersinia enterocolitica from raw and pasteurized milk from northern Iran. Int. J. Food Microbiol. 94:87-91.

Subha, B., D. Ramakrishnan, and V. Suganthi. 2009. Antimicrobial resistance pattern of selected Yersinia enterocolitica isolates from raw cow milk and pork samples of Namakkal District, Tamilnadu, South India. Glob. J. Environ. Res. 3:169-177.

Sulakvelidze, A. 2000. Yersiniae other than Y. enterocolitica, Y. pseudotuberculosis, and $Y$. pestis: The ignored species. Microbes Infect. 2:497-513.

Tacket, C. O., J. P. Narain, R. Sattin, J. P. Lofgren, C. Konigsberg, R. C. Rendtorff, A. Rausa, B. R. Davis, and M. L. Cohen. 1984. A multistate outbreak of infections caused by Yersinia enterocolitica transmitted by pasteurized milk. JAMA 251:483-486.

Tan, L. K., P. T. Ooi, and K. L. Thong. 2014. Prevalence of Yersinia enterocolitica from food and pigs in selected states of Malaysia. Food Contr. 35:94-100.

Thoerner, P., C. B. Kingombe, K. Bögli-Stuber, B. Bissig-Choisat, T. Wassenaar, J. Frey, and T. Jemmi. 2003. PCR detection of virulence genes in Yersinia enterocolitica and Yersinia pseudotuberculosis and investigation of virulence gene distribution. Appl. Environ. Microbiol. 69:1810-1816.

von Tils, D., I. Blädel, M. A. Schmidt, and G. Heusipp. 2012. Type II secretion in Yersinia - a secretion system for pathogenicity and environmental fitness. Front. Cell. Infect. Microbiol. 2:160.

Wauters, G., K. Kandolo, and M. Janssens. 1987. Revised biogrouping scheme of Yersinia enterocolitica. Contrib. Microbiol. Immunol. 9:14-21.

Weagant, S., and P. Feng. 2001. Yersinia. Pages 421-428 in Compendium of Methods for the Microbiological Examination of Foods, 3th ed. F. Pouch Downes and K. Ito, ed. American Public Health Association, Washington DC.

Yucel, N., and H. Ulusoy. 2006. A Turkey survey of hygiene indicator bacteria and Yersinia enterocolitica in raw milk and cheese samples. Food Contr. 17:383-388. 